\title{
EMERGING NOVEL NANOPHARMACEUTICALS FOR DRUG DELIVERY
}

\author{
ABISHEK WADHWA, VASHISH MATHURA, SHAILA ANGELA LEWIS* \\ Department of Pharmaceutics, Manipal College of Pharmaceutical Sciences, Manipal Academy of Higher Education, Manipal, Karnataka, \\ India. Email: s.lewis@manipal.edu
}

Received: 06 February 2018, Revised and Accepted: 14 April 2018

ABSTRACT

Nanotechnology is an area of growing public interest. Employing nanotechnology in the field of drug delivery has led to the advent of nanopharmaceuticals. Nanopharmaceuticals are bound to surmount various obstacles that the field of pharmacy is currently facing by offering various advantages thereby, a promising potential to formulate advanced medicines with fewer adverse effects. Extensive research is in place, thus instigating the development of novel drug delivery systems, such as carbon nanotubes, nanosponges, nano wafers, and nanofibers, to name a few. Since their inception, these nanopharmaceuticals have advanced significantly regarding their preparation strategy and scope of applications. This article aims to review the merits, limitations, and scope of these aforementioned delivery systems.

Keywords: Nanopharmaceuticals, Nanowafers, Nanosponges, Nanofibres, Carbon nanotubes.

(C) 2018 The Authors. Published by Innovare Academic Sciences Pvt Ltd. This is an open access article under the CC BY license (http://creativecommons. org/licenses/by/4. 0/) DOI: http://dx.doi.org/10.22159/ajpcr.2018.v11i7.25149

\section{INTRODUCTION}

Nanopharmaceuticsis the branch of science that deals with the application of the principles of nanotechnology (the science of material featuring between $10^{-9}$ and $10^{-7} \mathrm{~m}$ ) in pharmaceutics [1]. The nanoscopic size of these delivery systems helps in altering the aspects of a drug, including the bioavailability, bio-distribution, and pharmacokinetics. Nanoscaling the drug is another well-established technique for altering the properties [2]. Nanopharmaceuticals have unique properties due to their small size-it is this small size that allows them to reach places in the human body where larger particles do not have access to. For systemic applications, the generally accepted diameter of nanopharmaceuticals is in the range of 10-100 nm, with minimum surface charge [3]. Nanopharmaceuticals have a promising potential in the area of tissue engineering, in the field of drug delivery and diagnostics among many others. Current assertions of nanotechnology in pharmaceutical field are instigation of bioactive surfaces, advanced diagnostic, biomarker, image enhancement device, biosensor, implant technology, nanocarrier, nanomedicine, nanorobots, and tissue engineering to name a few [4]. Principally, nanopharmaceutical formulations are colloidal in nature of range 10-1000 $\mathrm{nm}$ in size and extensively used in drug delivery systems [5]. The purpose of the biomaterials employed in this field is primarily to improve drug delivery systems, imaging, and diagnostic technologies while the nanoscale materials are widely used in other industries such as electronics and optics [6,7]. The advantages of nanoparticle drug formulations include improved solubility, enhanced dissolution rate, improved oral bioavailability, improved dose proportionality, suitability for administration by all routes, and the possibility of sterile filtration due to decreased particle size range [7].

\section{CARBON NANOTUBES (CNTS)}

CNTs are allotropes of carbon with a tube-shaped structure. The diameter of the tubes are in the nanometer scale (can be as thin as a few nm yet having a length up to 100 microns). They have a thermal conductivity, mechanical and electrical properties. Nowadays, CNTs have found use in the medical field as they can be used for gene delivery to cells and organs as well as tissue regeneration [8].

CNTs can be classified as single-walled nanotubes and multi-walled nanotubes. As the name suggests, single-walled CNTs consist of one layer forming a cylinder while the multi-walled nanotubes comprise several cylindrical layers each having a diameter greater than the other. The chemical bonding in the tubes is best described by orbital hybridization (sp2-hybrid carbon atoms) which accounts for the unique strength of CNTs.

CNTS are widely researched in the field of drug delivery and biosensing methods for disease treatment and health monitoring. Table 1 lists some of the drugs explored for delivery using CNTs as carriers.

\section{FUNCTIONALIZATION OF CNTS}

It is the process of attaching an organic/inorganic molecule to the tubular structure of CNTs. This is done in an attempt to alter the physicochemical properties of the tube. Functionalization can be done through four methods: Noncovalent functionalization, covalent functionalization, endohedral filling and external decoration with inorganic materials [9].

\section{ADVANTAGES OF CNTS}

1. They have high electrical and thermal conductivity [10].

2. Due to their chemical bonding, they have unique tensile strength, and they have very high flexibility and elasticity.

3. They are available in small sizes which is helpful in penetrating tumors through the small holes or for the transportation of DNA.

4. They have a high surface area to volume ratio which aids in the effective transportation of molecules and rapid release. They also can contain a considerable amount of contents [11].

\section{DISADVANTAGES OF CNTS}

Health hazard:

1. Studies showed that the body could tolerate CNTs of relatively low length but as the length increased the use of the latter constituted some risks. Long tubes produced inflammation in sensitive tissues surrounding organs [12].

2. If CNTs are inhaled, due to their incredibly small size, it could lead to cancer (mesothelioma-a cancer form associated with asbestos) [13].

\section{MANUFACTURE OF CNTS [14]}

The following are the methods which can be employed for the production of CNTs: 
Table 1: Application of CNTs as carriers for drug delivery

\begin{tabular}{lll}
\hline Drug & Indication & Reference \\
\hline Amphotericin B & Anti-fungal & {$[23]$} \\
Cisplatin & Cancer (sarcoma, carcinoma) & {$[24]$} \\
Doxorubicin & Cancer & {$[25]$} \\
Epirubicin & Breast cancer & {$[26]$} \\
Oxaliplatin & Metastasized rectal cancer & {$[27]$} \\
Paclitaxel & Cancer & {$[28]$} \\
\hline
\end{tabular}

1. Arc discharge method

2. Laser method

3. Chemical vapor deposition method.

\section{ARC DISCHARGE METHOD}

This method is the simplest and most probably the easiest way to produce multi-walled CNTs. This technique produces a complex mixture of components which require purification to obtain the CNTs. It involves the arc-vaporization of two carbon electrodes placed in such a way that they are separated by a small gap in a closed environment filled with an inert gas at low pressure. A direct current (50-100 A) driven by a potential difference of $20 \mathrm{~V}$ generates a high-pressure discharge between the electrodes causing the vaporization of one of the electrode's surface forming a rod-shaped deposit on the other carbon electrode.

\section{LASER METHOD}

This technique is also known as laser ablation method and it is used to produce high purity single-walled nanotubes.

Conditions used in this process are as follows:

- Argon at $67 \mathrm{kPa}$

- A flow rate of approximately $3 \mathrm{~mm} / \mathrm{s}$, and

- $25 \mathrm{~mm}$ inner tube.

The process is carried out by laser vaporization of a graphite rodcontaining nickel and cobalt at $1200^{\circ} \mathrm{C}$ in flowing argon followed by treatment by heat in a vacuum at $1000^{\circ} \mathrm{C}$ to eliminate $\mathrm{C} 60$ and other fullerenes.

The process is done using two successive laser pulses: The first laser breaks the graphite rod into large particles while the second laser breaks the large particles produced by the first laser producing smaller particles which are fed to the growing CNT. The use of 2 lasers helps in reducing the amount of carbon deposited as soot.

One of the major drawbacks associated with these two methods is that it is difficult to scale up the production to a larger industrial scale, that is, they can be used to produce only a little amount of CNTs at a time.

\section{CHEMICAL VAPOUR DEPOSITION METHOD}

This method can be used to produce both single-walled and multiwalled CNTs. It can be used to produce large amounts of CNTs. It involves the catalytic vapor deposition of acetylene over cobalt and iron catalysts supported on silica. The amount of cobalt catalyst determines the activity of carbon deposition and the $\mathrm{pH}$ of the catalyst determines the selectivity of the CNT.

Carbon nanostructure with open ends was produced using acetylene at reaction temperatures of $545^{\circ} \mathrm{C}$ and $900^{\circ} \mathrm{C}$ for Nickel catalyzed and uncatalyzed processes, respectively.

High yields of single-walled CNT can be produced by the deposition of the $\mathrm{H} 2 / \mathrm{CH} 4$ mixture over-dispersed metal particles (nickel, cobalt, and iron) on magnesium oxide at $1000^{\circ} \mathrm{C}$.

\section{APPLICATIONS OF CNTS}

\section{Drug delivery}

Drugs can be attached to the CNTs on its surface or inside the tube which is then introduced into the patient through oral route or by injection. Cells ingest the CNTs and the tube releases its content into the cell, thus leading to drug delivery [15].

Drug release from the CNT is achieved at a faster rate than when compared to traditional dosage forms due to a large surface area to volume ratio.

\section{Cancer therapy}

CNTs are used as drug carriers to bring the anticancer drugs to the target site. The efficacy of present anticancer drugs is limited due to their narrow therapeutic window, systemic toxicity, and resistance by cells. CNTs can cross cytoplasmic and nuclear membranes, reaching the target cells in an intact form thus increasing the concentration of anticancer drugs at the target site [16]

The high surface area of CNTs allows the attachment of multiple drugs. CNTs can also be used for antitumor immunotherapy. This involves the stimulation of the immune system to combat the tumor cells. A cancer vaccine is incorporated in the nanotube and injected into the body to stimulate the immune system $[17,18]$.

\section{Infection therapy}

Antimicrobial agents can be carried by functionalized CNTs and then be transported to mammalian cells. This method not only increases the therapeutic concentration at the target site but also reduces the toxicity of the antimicrobial agent in the systemic circulation.

\section{For gene therapy by DNA delivery}

Gene therapy is the process of correcting a defective gene by inserting a DNA molecule into the cell nucleus. This DNA transfer can be achieved by the use of CNTs. When inserted into the tube, the DNA molecule is protected from enzymatic breakdown and nucleic acid binding proteins [19]. It has been found that nanoparticles can penetrate hair follicle canal, thus allowing nanoparticulate formulations to be used selective gene delivery [20].

\section{For the treatment of broken bones}

CNTs imitate the role of collagen as the scaffold material formation for the growth of hydroxyapatite into bone (hydroxyapatite crystals and collagen fibers are components of the bone tissue) [20].

\section{Tissue regeneration and artificial implants}

CNTs are extensively used for the development of scaffolds due to the following reasons: biocompatibility, resistance to biodegradation, and capability for functionalization to improve organ regeneration. CNTs can be used to improve the conductivity and mechanical strength of tissue scaffolding [21].

\section{Neurodegenerative diseases (Alzheimer's disease)}

Due to their very small size, CNTs can easily cross the blood-brain barrier and thus can be used along with drugs to target the brain to treat neurodegenerative diseases $[21,22]$.

\section{Diagnostic purposes}

CNTs can be used as biosensors for the detection of various analytes.

\section{NANOSPONGES}

Nanosponges are hypercrosslinked polymer based virus-sized sponges, which can be infused with various drugs. These virus-sized sponges offer high drug loading compared to other nanocarriers. They can move throughout the biological system until they come in contact with the definite target site following which they adhere to the surface and deliver the drug in a controlled and predictable manner [29]. Nanosponges have wide application in drug delivery (Table 2). 
Table 2: Applications of nanosponges

\begin{tabular}{lll}
\hline Drug & Indication & Reference \\
\hline Alprostadil & Erectile dysfunction & {$[46]$} \\
Camptothecin & Prostate tumor and thyroid cancer & {$[47,48]$} \\
Cefadroxil & Broad spectrum antibiotic & {$[49]$} \\
Celecoxib & NSAID & {$[50]$} \\
Dexamethasone & Ocular infection, brain tumors & {$[51,52]$} \\
Gabapentin & Epilepsy & {$[53]$} \\
Heparin & Anticoagulant & {$[54]$} \\
Itraconazole & Antifungal & {$[55]$} \\
Nifedipine & Angina pectoris & {$[56]$} \\
Paclitaxel & Cancer & {$[45]$} \\
Resveratrol & Inflammation, breast cancer & {$[57]$} \\
Rilpivirine & HIV & {$[58]$} \\
Tamoxifen & Breast cancer & {$[59]$} \\
Quercetin & Anticancer & {$[60]$} \\
\hline
\end{tabular}

NSAID: Nonsteroidal anti-inflammatory drug

\section{ADVANTAGES [30-36]}

1. Predictable releases: Nanosponges do not show burst effect upon reaching the target.

2. The controlled release nanoparticle drug delivery system may be instigated to deliver anticancer therapies, like injecting the drug directly into the tumor site.

3. Effective release of drug: Since the drug releases directly at the tumor site instead of moving freely through the body, it is more effective for a given dosage. Furthermore, they have fewer side effects as smaller amounts of the drug interact with the healthy tissues.

4. Encapsulating the anticancer drug in nanosponge permits the use of lipophilic drugs (low solubility in water) since nanosponge particles are soluble in water.

5. Improved stability (over a range of $\mathrm{pH} 1-11$; temperature up to $130^{\circ} \mathrm{C}$ ).

6. Enhanced elegance and flexibility of formulation. Nanosponge systems are non-irritant, nonmutagenic, nonallergic, and nontoxic.

7. A nanosponge provides an extended-release action (continuous action over a period of $12 \mathrm{~h}$ ).

\section{DISADVANTAGES/LIMITATIONS}

1. Nanosponges can incorporate only molecules which are small in size [37].

2. Nanosponges may either be in para-crystalline or in crystalline form. The extent of crystallization decides the loading capacity of nanosponges [37].

\section{POLYMERS USED IN NANOSPONGE PREPARATION}

Polymers and crosslinkers are crucial in the fabrication of nanosponges. Polymer type decides the formation and release, whereas crosslinker converts molecular cavities into three-dimensional nanoporous structures [37].

a. Polymers: Cyclodextrins and its derivatives such as methyl $\beta$-cyclodextrin, alkyloxycarbonyl cyclodextrins, 2-hydroxypropyl $\beta$-cyclodextrins; hyper cross-linked polystyrenes, copolymers like poly(valerolactone-allylvalerolactone) and poly(valerolactone-allylval erolactoneoxepanedione), ethyl cellulose and polyvinyl alcohol (PVA).

b. Crosslinkers: Diaryl carbonates, Diphenyl carbonate, diisocyanates, carbonyldiimidazoles, pyromelliticanhydride, epichloridrine, carboxylic acid dianhydrides, glutaraldehyde, 2,2-bis(acrylamido) acetic acid and dichloromethane have been reported as crosslinkers.

\section{PREPARATION OF NANOSPONGES}

\section{Emulsion solvent diffusion method}

Ethyl cellulose and PVA are used in different ratios to prepare nanosponges. The dispersed phase consisting of the drug and ethylcellulose is dissolved in dichloromethane and gradually added to a certain quantity of PVA in an aqueous continuous phase. The reaction mixture is mixed at $1000 \mathrm{rpm}$ for $120 \mathrm{~min}$. The nanosponges thus prepared are obtained by filtration and are further kept for drying in the oven at $400^{\circ} \mathrm{C}$ for $24 \mathrm{~h}$. To ensure the removal of residual solvent, the dried nanosponges are stored in vacuum desiccators [38].

\section{Ultrasound-assisted synthesis}

This method of preparation involves the reaction of polymers with the cross-linkers under the effect of sonication. This is done in the absence of a solvent. The nanosponges formed are uniform in size and spherical in shape. The polymer and the cross-linker are mixed in a certain molar ratio in the flask. The flask is placed in an ultrasound bath of water and is heated to $90^{\circ} \mathrm{C}$. The mixture is then sonicated for $5 \mathrm{~h}$. Once the mixture cools down, the product is broken forcibly. The non-reacted polymer is removed by washing the product with water, and consequently, soxhlet extraction with ethanol is done to cleanse the product. The final product is then dried under the vacuum and stored at $25^{\circ} \mathrm{C}$ until future use [38].

\section{Hyper cross-linked $\beta$-cyclodextrins}

Dimethyl formamide (DMF) is taken in a round-bottomed flask, anhydrous $\beta$-cyclodextrin is added to obtain complete dissolution. Carbonyl di-imidazole $(61.42 \mathrm{~m} \mathrm{~mol})$ is subsequently added. The solution is left undisturbed to react for $4 \mathrm{~h}$ at $1000 \mathrm{C}$. After the completion of condensation polymerization, the transparent block of hyper cross-linked cyclodextrin is roughly ground followed by addition of an excess of deionized water to remove DMF. Unreacted reagents or residual by-products are eliminated by soxhlet extraction with ethanol.

A white powder is obtained, and it is allowed to dry in an oven at $60^{\circ} \mathrm{C}$ overnight. The fine powder obtained is dissolved in water. The portion that remained suspended in water is recovered and lyophilized. The obtained nanosponges are spherical in shape and sub-micron in dimension [39].

\section{Loading of the drug into nanosponges}

Nanosponges employed for drug delivery should undergo a pretreatment to attain an average particle size of below $500 \mathrm{~nm}$. The nanosponges are suspended in water followed by sonication to break aggregates if any. The suspension is then centrifuged to obtain the colloidal fraction after which the supernatant is separated, and the sample is dried by freeze drying. An aqueous suspension of nanosponge is prepared, and an excess amount of drug is dispersed in the latter. Constantly, stir the suspension for the specific time required for complexation. The complexed drug is then separated from the uncomplexed drug by centrifugation soon after complexation takes place, where the uncomplexed drug is the undissolved part. The solid crystals of nanosponges are obtained, either by freeze-drying or solvent evaporation [39].

\section{Solvent method}

The polymer is added to a suitable solvent, primarily a polar aprotic solvent such as DMF or dimethylsulfoxide. This mixture is added to crosslinker (e.g., carbonyl di-imidazole and dimethyl carbonate) in excess quantity; the required ratio for crosslinker/molar ratio is as 1:4. The reaction is carried out at a temperature ranging from $100^{\circ} \mathrm{C}$ to the reflux temperature of the solvent, and the time ranging from 1 to $48 \mathrm{~h}$. As soon as the reaction is completed, the solution is allowed to cool to room temperature, and the product is added to a large quantity of bidistilled water and product is recovered by filtration under vacuum and subsequently purified by prolonged soxhlet extraction with ethanol. Finally, the product is dried under vacuum and ground in a mechanical mill to produce a homogeneous powder [40].

\section{Factors influencing the formulation}

1. Polymer type: Formation and the potential of nanosponges can be influenced. Cavity size of nanosponges should be appropriate for complexation.

2. Temperature alteration: Drug/nanosponges complexation can be affected by temperature alterations. As the temperature increases, the magnitude of apparent stability constant of the drug decreases possibly due to the reduction of drug interaction forces.

3. Preparation method: Drug complexation can be affected by the method of loading drug into nanosponges. Nature of drug and polymer alter the effectiveness of the method. 
4. The degree of substitution: The type, number, position of the substituent on parent molecule can greatly influence the nanosponges and hence, its complexation is affected.

\section{APPLICATIONS OF NANOSPONGES}

\section{Topical agents (e.g., econazole nitrate-antifungal)}

Nanosponge delivery system is the exclusive method for controlled release of topical agents and retention of drug form on the skin. Topical nanosponges can be easily formulated, for example, local anesthetics, antifungal, and antibiotics. With current topical medicaments, rashes or worse adverse effects can be observed when active pharmaceutical ingredients enter the skin. On the contrary, nanosponges allow an even and sustained rate of release, reducing irritation while maintaining efficiency. A variety of formulations, including gel, lotion, cream, ointment, liquid, or powder can be incorporated with nanosponges [41].

\section{Solubility enhancement (e.g., itraconazole)}

Nanosponges can be used to enhance the solubility and rate of dissolution of poorly soluble drugs while providing a controlled release profile. However, molecular dimensions and conformation are vital factors altering complexation process and hence may not be applicable to all molecules. Nanosponges of cefpodoxime proxetil have shown a better dissolution rate than regular cefpodoxime proxetil [39].

\section{Sustained delivery (e.g., acyclovir)}

Acyclovir is widely used to treat herpes simplex virus infections. The absorption of the drug in the GIT is slow, and thus appropriate concentrations of drug cannot be achieved at the target site. Encapsulation of acyclovir in nanosponges showed an increased efficacy of the drug $[42,43]$.

\section{Oxygen delivery systems}

Nanosponge has the capability of storing and releasing oxygen gradually over time. Oxygen-filled nanosponges can be used to supply oxygen to hypoxic tissues in certain diseases e.g., cyclodextrinnanosponges [44].

\section{Anticancer chemotherapy (e.g., paclitaxel)}

Drugs are incorporated in nanosponges, and they expose a targeting peptide that binds to radiation-induced cell surface receptor on the tumor. Once the nanosponge encounters a tumor cell, they adhere to the surface and trigger to release the contents. Such an example is paclitaxel (Taxol-20) [45].

\section{NANOWAFERS}

Nanowafer refers to a nanoscopic clear circular disc which can be administered on the surface of the eye and can resist blinking without getting dislocated. It consists of an assemblage of drug-loaded nanoreservoirs from which the drug will be released in a strongly controlled manner for several hours or days. The resultant contact time of the drug with the eye is increased, along with the net bioavailability because of its slow release. Once the drug is released, the wafer dissolves and gets dwindled [61]. The nanowafer is made up of a water-soluble polymer, which starts dissolving on application, thus releasing its payload. Sustained release and increased corneal permeability of nanowafer delivered doxycycline were compared with topical eye drops, increasing corneal residence time from a few minutes to up to $24 \mathrm{~h}$ in mice. These results demonstrate the immense scope for utilizing nanoporous materials to surmount the limitations of ocular drug delivery [62]. Nanowafers have tremendous potential in ocular drug delivery (Table 3).

\section{ADVANTAGES OF NANOWAFERS OCULAR DRUG DELIVERY (OVER EYE DROPS) [61,63-65]}

1. Does not need refrigeration.

2. Can be used for controlled release of an ocular drug.

3. Easy to fabricate.

4. Better patient compliance, especially for children and the elderly, because of lower dosing frequency (releases the drug over a period of hours or days).
5. Better bioavailability (on an average, only $5 \%$ of drug applied as an eye drop actually reaches past the cornea).

6. Fewer side effects (high systemic absorption using eye drops hence possibly causing significant side effects).

7. Increased therapeutic efficacy. (Does not get drained by nasolacrimal fluid).

8. Discrete doses and better quantification of the drug administered.

\section{DISADVANTAGES OF NANOWAFERS [66]}

1. Safety is controversial (their small size, which makes them useful, could also make them toxic).

2. Inadequate drug loading.

3. Further studies must be done to ensure that the vision would not be affected upon application of nanowafers.

4. Self-administration may be difficult for children and the elderly.

5. Nanowafers, being solid in nature, may be felt by the (often too sensitive) patients as an alien body in the eye, thus leading to a formidable physical and psychological impediment to user recognition and compliance.

\section{METHOD OF PREPARATION}

Nanowafers can be fabricated using various polymers, including PVA, polyvinylpyrrolidone, hydroxypropyl methylcellulose, and carboxy methylcellulose. The selection of these polymers is made based on their solubility in water, biocompatibility, mucoadhesivity, limpidity, and film-forming properties required to easily stick to a moist mucosal surface and adjust to the curvature of the eye. The nanowafers are prepared by the hydrogel template strategy with a few modifications. The process is explained in Fig. 1.

\section{APPLICATIONS (CURRENT AND FUTURE PROSPECTS)}

1. Once a week treatment of dexamethasone nanowafer has proven to be as effective as twice a day dexamethasone eye treatment in corneal wound healing and the suppression of corneal neovascularization [51].

2. Advancements in development of cysteamine (Cys) delivery nanowafer for corneal cystinosis (a rare metabolic disease, causing aggregation of cystine crystals in the cornea resulting in opacity of the cornea and loss of sight) The disease is currently managed with topical Cys eye drops (6-12 times daily throughout the patient's life), which result in side effects such as eye pain, redness, and ocular inflammation. Hence, compliance and treatment outcomes are severely jeopardized. To overcome these issues, scientists have developed a clinically translatable cysteaminenanowafer, which can be simply applied to the eye with a fingertip. During the drug release, cysteaminenanowafer gradually dissolves and fades away.

3. Drug delivery system along with lubricant action.

4. Nanowafer formulations for dry eye, ocular infections, eye injuries, and glaucoma.

\section{NANOFIBERS}

Nanofibers are fibers whose diameters are equal to or $<100 \mathrm{~nm}$.

Different polymers can be used to manufacture nanofibers of different diameters. Some of the polymers that can be used are natural polymers: Collagen, cellulose, gelatin, keratin synthetic polymers: Polylactic acid, polycaprolactone, polyurethane, and polylactic-co-glycolic acid [72,73].

Nanofibers can be manufactured by several methods mainly:

1. Electro-spinning

2. Self-assembly

3. Template synthesis

4. Thermal-induced phase separation.

Of all the manufacturing processes mentioned, electrospinning is the most preferred. This is due to its easy setup, continuous production of nanofibers using various polymers and the ability to produce ultrathin fibers with variable dimensions and orientations [74]. 
Table 3: Applications of nanowafers in drug delivery

\begin{tabular}{|c|c|c|}
\hline Drug & pathological use & Reference \\
\hline Axitinib & Corneal wound healing, corneal neovascularization & [61] \\
\hline Brimonidine & Antiglaucoma & [67] \\
\hline Ciprofloxacin & Antibiotic & [68] \\
\hline Cyclosporine & Immunomodulator: Increases tear production in dry eye disease & [64] \\
\hline Cysteamine hydrochloride & Treatment of corneal cystine crystal deposits in adults and children from 2 years of age with cystinosis & [69] \\
\hline Dexamethasone & Dry eye disease & [70] \\
\hline Doxycycline & Ocular rosacea & [61] \\
\hline Sorafenib & Ocular cancer & [61] \\
\hline Sunitinib & Ocular melanoma and Von Hippel-Lindau syndrome. & [61] \\
\hline
\end{tabular}

\section{The arrays of nanowells $(500 \mathrm{~nm}$ diameter and $500 \mathrm{~nm}$ depth) are fabricated on a silicon wafer by e-beam lithography.}

\section{Its poly(dimethylsiloxane) (PDMS) imprint is prepared.}

\section{A polymer solution is poured on the PDMS template.}

The PDMS template is baked.

The wells in the polymer wafer are filled with a solution of drug/ polymer mixture.

Fig. 1: Method of preparation of nanowafer

\section{ADVANTAGES OF USING NANOFIBERS AS PHARMACEUTICALS [75}

1. A high surface area to volume ratio

- Due to its very small dimensions, nanofibers have a high surface area to volume ratio, and this will cause them to react at a faster rate. The rate of diffusion of drugs incorporated in the fibers will be higher compared to usual drug delivery systems.

2. Numerous polymers can be used for manufacture

- Using the electrospinning method, a wide variety of polymers can be used to manufacture nanofibers. Although nanofibers are mainly prepared from polymers, it has been found out that nanofibers can be produced using ceramic and metal by electrospinning of their precursor material.

3. Ease of manufacture

- Different materials can be easily mixed to produce fibers by spinning.

4. Ease of functionalization

- The effectiveness of nanofibers can be achieved by simple blending of polymer solution before spinning or core-shell electrospinning setup.

- The fibers can also be easily deposited on surfaces with a lower static charge such as metal, glass, and microfibrous mat

5. Low cost of production and mass production is possible.

6. Nanofibers can be used as drug carriers for the controlled drug delivery of bioactive molecules.

\section{DISADVANTAGES OF NANOFIBERS}

The disadvantages of nanofibers are usually associated with its production method. While using electrospinning method, the drawbacks can be as follows:

1. The solvents used might be toxic and injurious to health.

2. Obtaining a 3D structure can be quite a tough task and obtaining the required pore size for medical applications is no difference.

3. The process also depends on several variables. (mentioned in the process of electrospinning).

\section{PROCESS OF MANUFACTURE OF NANOFIBERS [76-78]}

As mentioned earlier there are four methods for the manufacture of nanofibers:

1. Electrospinning

2. Self-assembly

3. Template synthesis

4. Thermal-induced phase separation.

Electrospinning is usually preferred due to its flexibility and costeffectiveness.

The process of electrospinning is explained in Fig. 2:

As depicted in Fig. 2, the polymer solution (polymer+solvent) is kept in a syringe connected to a high voltage supply. The solution is pumped 


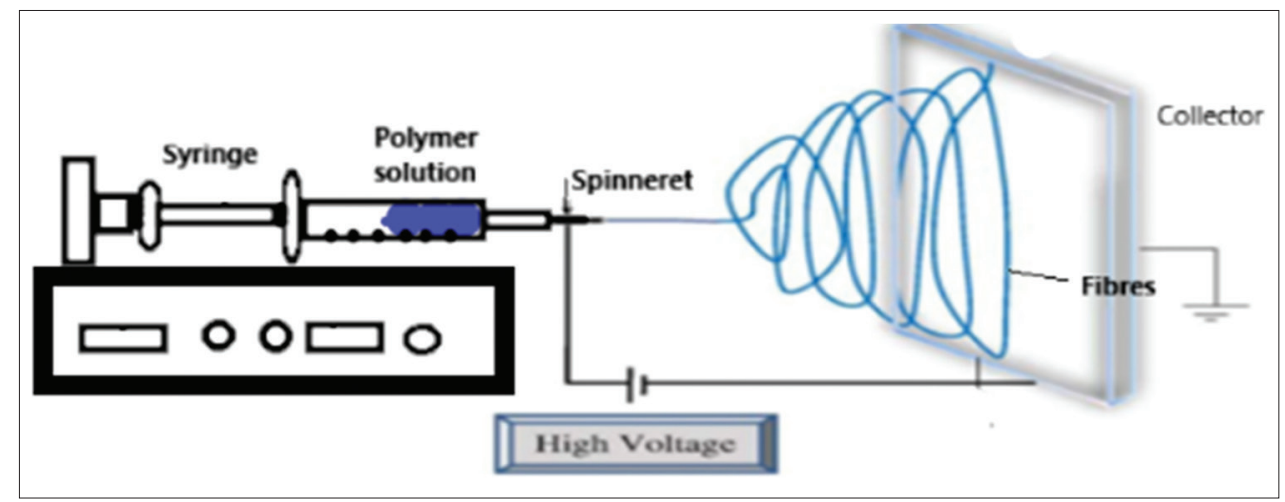

Fig. 2: Electrospinning process

from the syringe at a uniform rate, forming a droplet at the tip of the needle. When the surface tension is overcome by the electrostatic repulsion of charges within the solution, the droplet is ejected (forming a jet) towards the collector which is connected to the ground as shown in the diagram. During the travel from the needle to the collector the solvent gets evaporated, and the jet is elongated at very high strain rates.

Formation of nanofibers is achieved by repulsion occurring among charges resulting in high stretching of the polymer stream. At first, the stream flows straight. On the way to the collector, the jet is elongated by whipping and bending processes caused by electrostatic repulsion initiated at small bends in the fiber, until it is finally deposited on the collector. The thinning and elongation of this resultant fiber leads to the formation of uniform fibers. The coiling movement of the stream increases the path between the needle and the collector, resulting in a considerable stretching (nanometer diameter).

The main forces acting on the drop and the traveling jet are:

1. External electrostatic field

2. Electrostatic repulsion among the charges

3. Surface tension

4. Forces associated with the viscoelasticity of the polymer.

Parameters affecting the electrospinning process:

1. The viscosity of solution - a high viscosity will prevent the breakage of the jet during the process and maintain the fiber shape and prevent the formation of beads.

2. Solution surface tension and electrical conductivity.

3. The dielectric constant of the solvent.

4. Applied voltage.

5. The flow rate of solution and diameter of the needle.

6. The distance between needle and collector and type of collector used.

\section{APPLICATIONS OF NANOFIBERS (Table 4)}

\section{Drug delivery}

Nanofibers can be used as drug carriers. Due to their high surface area to volume ratio, drug release occurs at a faster rate resulting in an increased bioavailability of the drugs, especially for poorly soluble drugs $[79,80]$

\section{Wound healing}

These involve the use of nanofiber layers produced from biopolymers (chitosan, gelatin, collagen amongst others/combination of these materials).

They can be used as wound dressings for the support during the wound healing process. Other substances can be incorporated in the nanofibers during the wound healing process, for example, an antibacterial agent can be added when using nanofibers on contaminated wounds and growth factors can be added when the proliferation of dermal tissue is needed $[79,81]$.
Table 4: Applications of nanofibers in drug delivery

\begin{tabular}{lll}
\hline Drug & Indication & Reference \\
\hline Naproxen & NSAID & {$[86]$} \\
Vitamin A & Maintenance of immune system and & {$[87]$} \\
& vision & \\
Levothyroxine & Hypothyroidism & {$[88]$} \\
Fluconazole & Vaginal candidiasis & {$[89]$} \\
Insulin & Diabetes & {$[90]$} \\
Fusidic acid & Steroid antibiotic & {$[91]$} \\
Gentamicin & Anti-bacterial & {$[92]$} \\
Carmustine & Cancer & {$[93]$} \\
Doxorubicin & Cancer (breast cancer, bladder & {$[94]$} \\
& cancer, lymphoma) & \\
Taxol & Cancer & {$[95]$} \\
Tetracycline & Periodontal diseases & {$[96]$} \\
\hline
\end{tabular}

NSAID: Nonsteroidal anti-inflammatory drug

\section{Tissue engineering}

Nanofibers made from biopolymers (e.g., collagen) can act as substrates for culturing cells. Different scaffolds can be prepared for implantation. The scaffolds are prepared based on the mechanical and structural properties of the nanofibers. A patient's cells can be isolated and grown on nanofibers substrates which can be eventually used for tissue replacement purposes. Bioactive materials such as immunosuppressant and growth factor can be incorporated during the preparation of these scaffolds $[79,82,83]$

\section{Barrier textiles}

Textiles-containing hydrophobic nanofiber layers can be used as a barrier for bacterial contamination. The barrier textiles in which the nanofiber layer are enclosed between a carrier layer and a covering layer, are prepared as a "sandwich." (Melt-blown non-woven). These particular textiles can be used as surgical dressings [84].

\section{Topical delivery}

Nanofibers have been modified to be able to accommodate vitamins and gold particles to be used as a facial mask for topical delivery. Existing beauty face masks can cause the degradation of sensitive ingredients (e.g., ascorbic acid). Thus, to circumvent this difficulty, a novel face mask has been manufactured to be able to contain and deliver multiple skin nutrients [85].

\section{CONCLUSION}

Nanopharmaceuticals are an integral part of modern medicine and drug delivery system. They have engendered a wide scope for revolutionizing the health-care sector in providing the drugs at the localized targets for a sufficient duration. These novel delivery systems enhance the solubility of poorly soluble drugs, decrease the dosing frequency and improve bioavailability. Nanowafers, in particular, have led to the formulation of novel formulations for indications of glaucoma, dry eye, corneal cystinosis and other eye-related problems such as injuries and 
infections. In general, nanopharmaceuticals has assisted in formulating advanced dosage forms and finished products. Currently, extensive research is in progress to discover wider horizons for the applications as well as to minimize the limitations of this technology.

\section{AUTHORS' CONTRIBUTIONS}

Abishek Wadhwa-Studied and wrote about nanosponges and naowafers. Vashish Mathura-Studied and wrote about CNTs and nanofibres. Dr. Shaila Angela Lewis-Helped in structuring and proofreading the paper.

\section{CONFLICT OF INTEREST}

This statement is to certify that all authors have seen and approved the manuscript being submitted. We warrant that the article has not received prior publication and is not under consideration for publication elsewhere. On behalf of all co-authors, the corresponding author shall bear full responsibility for the submission.

\section{REFERENCE}

1. Gaur A, Bhatia AL. Nanopharmaceuticals: An overview. Asian J Exp Sci 2008;22:51-62.

2. Ali J. Nanopharmaceutics. Int J Pharm Invest 2011;1:61.

3. Davis ME. Nanoparticles for systemic medicines and imaging agents. Nanotech L Bus 2006;3:255.

4. Chavda H. Nanopharmaceuticals: The pharmaceuticals of the present era. Ely J Pharm Res 2016;1:106e.

5. Panda BP, Varaprasad R, Priyanka K, Swain RP. Current trends in design and development of nanopharmaceutical dosage forms. Bioequiv Bioavailab Int J 2017;1:104.

6. Koopaei NN, Abdollahi M. Erratum to: Opportunities and obstacles to the development of nanopharmaceuticals for human use. Daru 2016;24:25

7. Horstkotte E, Odoerfer KI. Towards improved therapies using nanopharmaceuticals: Recent patents on pharmaceutical nanoformulations. Recent Pat Food Nutr Agric 2012;4:220-44.

8. Osmani RM, Kulkarni AS, Aloorkar NH, Bhosale RR, Ghodake PP, Harkare BR. Carbon nanotubes: An impending carter in therapeutics. Int J Pharm Clin Res 2014;6:84-96.

9. Tobias G, Mendoza E, Ballesteros B. Functionalization of carbon nanotubes. In: Encyclopedia of Nanotechnology. Netherlands: Springer; 2012. p. 911-9.

10. Lekawa-Raus A, Patmore J, Kurzepa L, Bulmer J, Koziol K. Electrical properties of carbon nanotube based fibers and their future use in electrical wiring. Adv Funct Mater 2014;24:3661-82.

11. Kostarelos K, Bianco A, Prato M. Promises, facts and challenges for carbon nanotubes in imaging and therapeutics. Nat Nanotechnol 2009:4:627-33.

12. Firme $\mathrm{CP} 3^{\text {rd }}$, Bandaru PR. Toxicity issues in the application of carbon nanotubes to biological systems. Nanomedicine 2010;6:245-56.

13. Luleå University of Technology. Researcher Warns of Health Risks with Carbon Nanotubes. Science Daily. Sweden: Science Daily; 2011

14. Rafique MM, Iqbal J. Production of carbon nanotubes by different routes-a review. J Encapsulation Adsorpt Sci 2011;1:29

15. Zhang W, Zhang Z, Zhang Y. The application of carbon nanotubes in target drug delivery systems for cancer therapies. Nanoscale Res Lett 2011;6:555

16. Usui Y, Haniu H, Tsuruoka S, Saito N. Carbon nanotubes innovate on medical technology. Med Chem 2012;2:1-6.

17. Lay CL, Liu J, Liu Y. Functionalized carbon nanotubes for anticancer drug delivery. Expert Rev Med Devices 2011;8:561-6.

18. Pantarotto D, Singh R, McCarthy D, Erhardt M, Briand JP, Prato M, et al. Functionalized carbon nanotubes for plasmid DNA gene delivery. Angew Chem 2004;116:5354-8.

19. Bekyarova E, Ni Y, Malarkey EB, Montana V, McWilliams JL, Haddon RC, et al. Applications of carbon nanotubes in biotechnology and biomedicine. J Biomed Nanotechnol 2005;1:3-17.

20. Dey PR, Das NI. Carbon nanotubes: It's role in modern health care. Int J Pharm Pharm Sci 2013;5:9-13.

21. Digge MS, Moon RS, Gattani SG. Applications of carbon nanotubes in drug delivery: A review. Int J PharmTech Res 2012;4:839-47.

22. Liao H, Paratala B, Sitharaman B, Wang Y. Applications of carbon nanotubes in biomedical studies. Methods Mol Biol 2011;726:223-41.

23. Wu W, Wieckowski S, Pastorin G, Benincasa M, Klumpp C, Briand JP, et al. Targeted delivery of amphotericin B to cells by using functionalized carbon nanotubes. Angew Chem Int Ed Engl 2005;44:6358-62.

24. Hilder TA, Hill JM. Modelling the encapsulation of the anticancer drug cisplatin into carbon nanotubes. Nanotechnology 2007;18:275704.

25. Vashist SK, Zheng D, Pastorin G, Al-Rubeaan K, Luong JH, Sheu FS. Delivery of drugs and biomolecules using carbon nanotubes. Carbon 2011:49:4077-97.

26. Chen Z, Pierre D, He H, Tan S, Pham-Huy C, Hong H, et al. Adsorption behavior of epirubicin hydrochloride on carboxylated carbon nanotubes. Int J Pharm 2011;405:153-61.

27. Wu L, Man C, Wang H, Lu X, Ma Q, Cai Y, et al. PEGylated multiwalled carbon nanotubes for encapsulation and sustained release of oxaliplatin. Pharm Res 2013;30:412.

28. Sobhani Z, Dinarvand R, Atyabi F, Ghahremani M, Adeli M. Increased paclitaxel cytotoxicity against cancer cell lines using a novel functionalized carbon nanotube. Int J Nanomedicine 2011;6:705-19.

29. Selvamuthukumar S, Anandam S, Krishnamoorthy K, Rajappan M. Nanosponges: A novel class of drug delivery system-review. J Pharm Pharm Sci 2012;15:103-11

30. Patel G, Patel JK. Use of a microsponge in drug delivery systems. Pharm Proc 2008; $158: 1$

31. Khopade AJ, Jain S, Jain NK. The microsponge. East Pharm 1996:39:49-53.

32. Jain N, Devi VK, Dang E. Uday bhosale: Micro sponges: A novel drug delivery system. APTI Bulletin 2013;15.

33. Vishwakarma A, Nikam P, Mogal R, Talele S. Review on nanosponges: A benefication for novel drug delivery. Int J PharmTech Res 2014;6:11-20.

34. Shivani S, Poladi KK. Nanosponges-novel emerging drug delivery system: A review. Int J Pharm Sci Res 2015;6:529.

35. Jilsha G, Viswanad V. Nanosponges: A novel approach of drug delivery system. Int J Pharm Sci Rev Res 2013;19:119-23.

36. Kaur G, Aggarwal G, Harikumar SL. Nanosponge: New colloidal drug delivery system for topical delivery. Indo Glob J Pharm Sci 2015;5:53-7.

37. Karalis V, Macheras P, Van Peer A, Shah VP. Bioavailability and bioequivalence: Focus on physiological factors and variability. Pharm Res 2008;25:1956-62.

38. Sharma R, Walker RB, Pathak K. Evaluation of the kinetics and mechanism of drug release from econazole nitrate nanosponge loaded carbapol hydrogel. Indian J Pharm Educ Res 2011;45:25-31

39. Setijadi E, Tao L, Liu J, Jia Z, Boyer C, Davis TP. Biodegradable star polymers functionalized with $\beta$-cyclodextrin inclusion complexes. Biomacromolecules 2009;10:2699-707.

40. Trotta F, Cavalli R, Tumiatti W, Zerbinati O, Roggero C, Vallero R, et al. Ultrasound-Assisted Synthesis of Cyclodextrin-Based Nanosponges. United States Patent Application US 11/630,403. 2008 Sep 4.

41. Patel EK, Oswal RJ. Nanosponge and micro sponges: A novel drug delivery system. Int J Res Pharm Chem 2012;2:237-44.

42. Lala R, Thorat A, Gargote C. Current trends in $\beta$-cyclodextrin based drug delivery systems. Int J Res Ayurveda Pharm 2011;2:1520-6.

43. Alongi J, Poskovic M, Frache A, Trotta F. Role of $\beta$-cyclodextrin nanosponges in polypropylene photooxidation. Carbohydr Polym 2011;86:127-35.

44. Cavalli R, Akhter AK, Bisazza A, Giustetto P, Trotta F, Vavia P, et al. Nanosponge formulations as oxygen delivery systems. Int $\mathrm{J}$ Pharm 2010;402:254-7.

45. Marcano DC, Shin CS, Lee B, Isenhart LC, Liu X, Li F, et al. Synergistic cysteamine delivery nanowafer as an efficacious treatment modality for corneal cystinosis. Mol Pharm 2016;13:3468-77.

46. Singh D, Soni GC, Prajapati SK. Recent advances in nanosponges as drug delivery system: A review. Eur J Pharm Med Res 2016;3:364-71.

47. Shankar S, Linda P, Loredana S, Francesco T, Pradeep V, Dino A, et al. Cyclodextrin-based nanosponges encapsulating camptothecin: Physicochemical characterization stability and cytotoxicity. Eur J Pharm Biopharm 2013;74:193-201

48. Gigliotti CL, Ferrara B, Occhipinti S, Boggio E, Barrera G, Pizzimenti S, et al. Enhanced cytotoxic effect of camptothecin nanosponges in anaplastic thyroid cancer cells in vitro and in vivo on orthotopic xenograft tumors. Drug Deliv 2017;24:670-80.

49. Dubey P, Sharma HK, Shah S, Tyagi CK, Chandekar AR, Jadon RS. Formulations and evaluation of cyclodextrin complexed ceadroxil loaded nanosponges. Int J Drug Delivery 2017;9:84-100.

50. Gangadharappa HV, Prasad SM, Singh RP. Formulation, in vitro and in vivo evaluation of celecoxib nanosponge hydrogels for topical application. J Drug Delivery Sci Technol 2017;41:488-501.

51. Swaminathan S, Vavia PR, Trotta F, Cavalli R. Nanosponges encapsulating dexamethasone for ocular delivery: Formulation design, physicochemical characterization, safety and corneal permeability 
assessment. J Biomed Nanotechnol 2013;9:998-1007.

52. Swaminathan S, Cavalli R, Trotta F. Cyclodextrin-based nanosponges: A versatile platform for cancer nanotherapeutics development. Wiley Interdiscip Rev Nanomed Nanobiotechnol 2016;8:579-601.

53. Rao MR, Bhingole RC. Nanosponge-based pediatric-controlled release dry suspension of gabapentin for reconstitution. Drug Dev Ind Pharm 2015;41:2029-36

54. Choi WI, Sahu A, Vilos C, Kamaly N, Jo SM, Lee JH, et al. Bioinspired heparin nanosponge prepared by photo-crosslinking for controlled release of growth factors. Sci Rep 2017;7:14351.

55. Swaminathan S, Vavia PR, Trotta F, Torne S. Formulation of betacyclodextrin based nanosponges of itraconazole. J Inclusion Phenom Macrocyclic Chem 2007;57:89-94

56. Shringirishi M, Mahor A, Gupta R, Prajapati SK, Bansal K, Kesharwani P. Fabrication and characterization of nifedipine loaded $\beta$-cyclodextrin nanosponges: An in vitro and in vivo evaluation. J Drug Delivery Sci Technol 2017;41:344-50.

57. Ansari KA, Vavia PR, Trotta F, Cavalli R. Cyclodextrin-based nanosponges for delivery of resveratrol: In vitro characterisation, stability, cytotoxicity and permeation study. AAPS PharmSciTech 2011;12:279-86

58. Zainuddin R, Zaheer Z, Sangshetti JN, Momin M. Enhancement of oral bioavailability of anti-HIV drug rilpivirine $\mathrm{HCl}$ through nanosponge formulation. Drug Dev Ind Pharm 2017;43:2076-84.

59. Lockhart JN, Stevens DM, Beezer DB, Kravitz A, Harth E. Dual drug delivery of tamoxifen and quercetin: Regulated metabolism for anticancer treatment with nanosponges. J Controlled Release 2015;220:751-7.

60. Lu Z, Bu C, Hu W, Zhang H, Liu M, Lu M, et al. Preparation and in vitro and in vivo evaluation of quercetin-loaded mixed micelles for oral delivery. Biosci Biotechnol Biochem 2018;82:238-46.

61. Yuan X, Marcano DC, Shin CS, Hua X, Isenhart LC, Pflugfelder SC, et al. Ocular drug delivery nanowafer with enhanced therapeutic efficacy. ACS Nano 2015;9:1749-58.

62. Kim J, Schlesinger EB, Desai TA. Nanostructured materials for ocular delivery: Nanodesign for enhanced bioadhesion, transepithelial permeability and sustained delivery. Ther Deliv 2015;6:1365-76.

63. Bian F, Shin CS, Wang C, Pflugfelder SC, Acharya G, De Paiva CS, et al. Dexamethasone drug eluting nanowafers control inflammation in alkali-burned corneas associated with dry eye. Invest Ophthalmol Vis Sci 2016;57:3222-30.

64. Pflugfelder SC. Broadly Applicable Nanowafer Drug Delivery System for Treating Eye Injuries. Houston, TX: Baylor College of Medicine Houston United States; 2017.

65. Patel A, Cholkar K, Agrahari V, Mitra AK. Ocular drug delivery systems: An overview. World J Pharmacol 2013;2:47-64.

66. Sikandar MK, Sharma PK, Visht S. Ocular drug delivery system: An overview. Int J Pharm Sci Res 2011;2:1168

67. Wang J, Williamson GS, Lancina II, Michael G, Yang H. Mildly crosslinked Dendrimer hydrogel prepared via aza-michael addition reaction for topical brimonidine delivery. J Biomed Nanotechnol 2017;13:1089-96.

68. Qin G, Zhu Z, Li S, McDermott AM, Cai C. Development of ciprofloxacin-loaded contact lenses using fluorous chemistry. Biomaterials 2017;124:55-64.

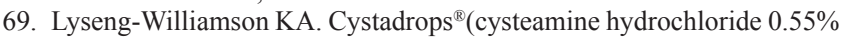
viscous eye-drops solution) in treating corneal cystine crystal deposits in patients with cystinosis: A profile of its use. Drugs Ther Perspect 2017;33:195-201.

70. Acharya G. The Dexamethasone Nanowafer: A Novel Method of Drug Delivery for Dry Eye Disease. Houston, Texas, USA: Baylor College of Medicine; 2015.

71. Richa V. A Novel Particle-Based in situ Gelling System for Delivering Hydrogen Sulfide at a Sustained Rate for Potential Application in Glaucoma and Retinal Neurodegeneration. PhD Diss., Creighton University; 2017.

72. Vasita R, Katti DS. Nanofibers and their applications in tissue engineering. Int J Nanomed 2006;1:15.

73. Khajavi R, Abbasipour M, Bahador A. Electrospun biodegradable nanofibers scaffolds for bone tissue engineering. J Appl Polym Sci 2016;133:2-19.
74. Li D, Xia Y. Electrospinning of nanofibers: Reinventing the wheel? Adv Mater 2004;16:1151-70.

75. Yu DG, Zhu LM, White K, Branford-White C. Electrospun nanofiberbased drug delivery systems. Health 2009;1:67.

76. Ramakrishna S. An Introduction to Electrospinning and Nanofibers. New Jersey, London, Singapore: World Scientific; 2005.

77. Bhardwaj N, Kundu SC. Electrospinning: A fascinating fiber fabrication technique. Biotechnol Adv 2010;28:325-47.

78. Karakaş H. Electrospinning of Nanofibers and There Applications. Istanbul Technical University, Textile Technologies and Design Faculty; 2015

79. Kim SE, Heo DN, Lee JB, Kim JR, Park SH, Jeon SH, et al. Electrospun gelatin/polyurethane blended nanofibers for wound healing. Biomed Mater 2009;4:044106.

80. Zhang Y, Lim CT, Ramakrishna S, Huang ZM. Recent development of polymer nanofibers for biomedical and biotechnological applications. J Mater Sci Mater Med 2005;16:933-46.

81. Xie Z, Paras CB, Weng H, Punnakitikashem P, Su LC, Vu K, et al. Dual growth factor releasing multi-functional nanofibers for wound healing. Acta Biomater 2013;9:9351-9.

82. Yoo HS, Kim TG, Park TG. Surface-functionalized electrospun nanofibers for tissue engineering and drug delivery. Adv Drug Deliv Rev 2009;61:1033-42.

83. Bagul R, Mahajan V, Dhake A. New approaches in nanoparticulate drug delivery system: A review. Int J Curr Pharm Res 2012;4:29-38.

84. Abrigo M, McArthur SL, Kingshott P. Electrospun nanofibers as dressings for chronic wound care: Advances, challenges, and future prospects. Macromol Biosci 2014;14:772-92.

85. Bangale MS, Sachin M, Gattani SG, Sakarkar DM. Recent nanotechnological aspects in cosmetics and dermatological preparations. Int J Pharm Pharm Sci 2012;4:88-97.

86. Görbitz $\mathrm{CH}$. Nanotube formation by hydrophobic dipeptides. Chemistry 2001;7:5153-9.

87. Taepaiboon P, Rungsardthong U, Supaphol P. Vitamin-loaded electrospun cellulose acetate nanofiber mats as transdermal and dermal therapeutic agents of vitamin A acid and vitamin E. Eur J Pharm Biopharm 2007;67:387-97.

88. Arduino C, Eandi M. Kinetics of thyroxine epicutaneous absorption. Pharmacol Res 1989;21:109-10.

89. Johal HS, Garg T, Rath G, Goyal AK. Advanced topical drug delivery system for the management of vaginal candidiasis. Drug Deliv 2016;23:550-63

90. Kashyap N, Viswanad B, Sharma G, Bhardwaj V, Ramarao P, Ravi Kumar MN, et al. Design and evaluation of biodegradable, biosensitive in situ gelling system for pulsatile delivery of insulin. Biomaterials 2007;28:2051-60.

91. Gilchrist SE, Lange D, Letchford K, Bach H, Fazli L, Burt HM. Fusidic acid and rifampicin co-loaded PLGA nanofibers for the prevention of orthopedic implant associated infections. J Controlled Release 2013;170:64-73.

92. Torres-Giner S, Martinez-Abad A, Gimeno-Alcañiz JV, Ocio MJ, Lagaron JM. Controlled delivery of gentamicin antibiotic from bioactive electrospun polylactide-based ultrathin fibers. Adv Eng Mater 2012;14:B112-22.

93. Westphal M, Hilt DC, Bortey E, Delavault P, Olivares R, Warnke PC, et al. A phase 3 trial of local chemotherapy with biodegradable carmustine (BCNU) wafers (Gliadel wafers) in patients with primary malignant glioma. Neuro Oncol 2003;5:79-88.

94. Steiniger SC, Kreuter J, Khalansky AS, Skidan IN, Bobruskin AI, Smirnova ZS, et al. Chemotherapy of glioblastoma in rats using doxorubicin-loaded nanoparticles. Int J Cancer 2004;109:759-67.

95. Zeng J, Xu X, Chen X, Liang Q, Bian X, Yang L, et al. Biodegradable electrospun fibers for drug delivery. J Controlled Release 2003;92:227-31.

96. Kenawy el-R, Bowlin GL, Mansfield K, Layman J, Simpson DG, Sanders EH, et al. Release of tetracycline hydrochloride from electrospun poly(ethylene-co-vinylacetate), poly(lactic acid), and a blend. J Control Release 2002;81:57-64. 